\title{
THE EFFECT OF SYMPATHOLYTIC AGENTS ON THE CARDIOVASCULAR RESPONSES PRODUCED BY THE INJECTION OF ACETYLSTROPHANTHIDIN INTO THE CEREBRAL VENTRICLES *
}

\author{
Janice L.STICKNEY ** and Benedict R.LUCCHESI \\ Department of Pharmacology, The Unversity of Michtgan Medical School, \\ Ann Arbor, Michtgan, USA
}

Received 3 December 1968

Accepted 20 December 1968

\begin{abstract}
J.L.STICKNEY and B.R.LUCCHESI, The effect of sympatholytic agents on the cardiovascular responses produced by the injection of acetylstrophanthidin into the cerebral ventricles, European J Pharmacol. 6 (1969) 1-7.

The administration of acetylstrophanthidin into the left lateral ventricle of dogs anesthetized with alphachloralose produces ventricular arrhythmias and a marked pressor response. The pressor response is not prevented by the intravenous or intraventricular administration of $d, l$-propranolol nor by reserpine-pretreatment. However, the centrally-induced pressor response is reversed by intravenously administered $d, l$-propranolol but not by $d$-propranolol. The mechanism by which $d, l$-propranolol exerts this effect is discussed. The ventricular arrhythmias did not occur after reserpine-pretreatment or after the intraventricular injection of $d, l$-propranolol. The arrhy thmias were affected by neither the intravenous administration of $d, l$-propranolol nor the intraventricular injection of $d$-propranolol.
\end{abstract}

Cardiac glycosides

Propranolol
Reserpine

Ventricular arrhy thmias
Lateral cerebral ventricle

Blood pressure

\section{INTRODUCTION}

The most frequently occurring mode of death following the intravenous administration of cardiac glycosides to dogs is ventricular fibrillation (Erlij and Mendez, 1964; Stickney et al., 1966). However, following either depletion of catecholamines with reserpine or beta-adrenergic receptor blockade with propranolol, cardiac arrest becomes the most frequent cause of death induced by cardiac glycosides (Stickney et al., 1966; Nash et al., 1964). The relationship between catecholamines and mode of death was first noted by Mendez et al. (1961) who observed that dogs with bilateral vagotomy died in ventricular fibrillation, but that ventricular fibrillation never

* This research was partially supported by Grant 2G198.

** Present address: Department of Pharmacology, University of California Medical Center, San Francisco, Californı 94122, USA. occurred after bilateral cardiac sympathectomy and ligation of the adrenal glands.

To explain the relation of sympathetic activity to the occurrence of ventricular fibrillation, Boyajy and Nash (1966) and Mendez et al. (1961) have suggested that death induced by cardiac glycosides is, in part, mediated by central nervous system mechanisms which in some way modify peripheral sympathetic nervous system activity. To further investigate this problem the present experiments studied the cardiovascular responses that followed the injection of acetylstrophanthidin into the left lateral ventricle.

\section{METHODS}

The experiments were performed on male, beagletype dogs that weighed between six and twelve kilograms. The animals were anesthetized with alphachloralose, $100 \mathrm{mg} / \mathrm{kg}$ administered intravenously. 
Blood pressure was recorded from the right femoral artery with a pressure transducer. The blood pressure and Lead II electrocardiogram were recorded contınuously on a Grass Model 7 polygraph. The Lead II electrocardıogram was also monitored contınuously on an oscilloscope. A catheter was placed in the left jugular vem for the systemic administration of drugs. Decamethonium, $1.0 \mathrm{mg} / \mathrm{kg}$, was administered intravenously to induce neuromuscular blockade. A Palmer respirator pump was used to ventilate the animal with room air.

The term central injection refers to the administration of a drug into the left lateral ventricle of the brain. The left lateral ventricle was located by using Horsely-Clarke coordinates (as modified by Lim et al., 1960) on a stereotaxic instrument. The dose of acetylstrophanthidin injected centrally was $10.0 \mu \mathrm{g} / \mathrm{kg}$ in an injection volume of $0.5-0.9 \mathrm{ml}$.

The effects of intraventricularly administered propranolol on pressor responses and cardiac arrhythmias elicited by the central injection of acetylstrophanthidin were studied. In two different series of experiments, $d$-propranolol and $d, l$-propranolol were injected into the left lateral ventricle, and acetylstrophanthidin injected into the same ventricle 15 min later. In other experiments, animals were pre- treated with reserpine, $0.1 \mathrm{mg} / \mathrm{kg}$ intramuscularly on two consecutive days; the animals were used on the fourth day.

In another group of animals the racemic mixture of propranolol was administered intravenously to block beta-adrenergic receptors before the central injection of acetylstrophanthidin.

In two additional groups of animals, either $d$-propranolol or $d, l$-propranolol was administered intravenously after the central injection of acetylstrophanthidın.

Acetylstrophanthidin was generously supplied by Eli Lilly and Company of Indianapolis, Indiana Both the racemic mixture and the $d$-isomer of propranolol (Inderal) were generously supplied by Ayerst Laboratories in New York, New York.

\section{RESULTS}

3.1. Control responses to the injection of acetylstrophanthidin into the left lateral cerebral ventricle

The dose of acetylstrophanthidin used here, 10 $\mu \mathrm{g} / \mathrm{kg}$, produces no observable responses when injected intravenously; however, in six out of six untreated animals marked cardiovascular responses fol-
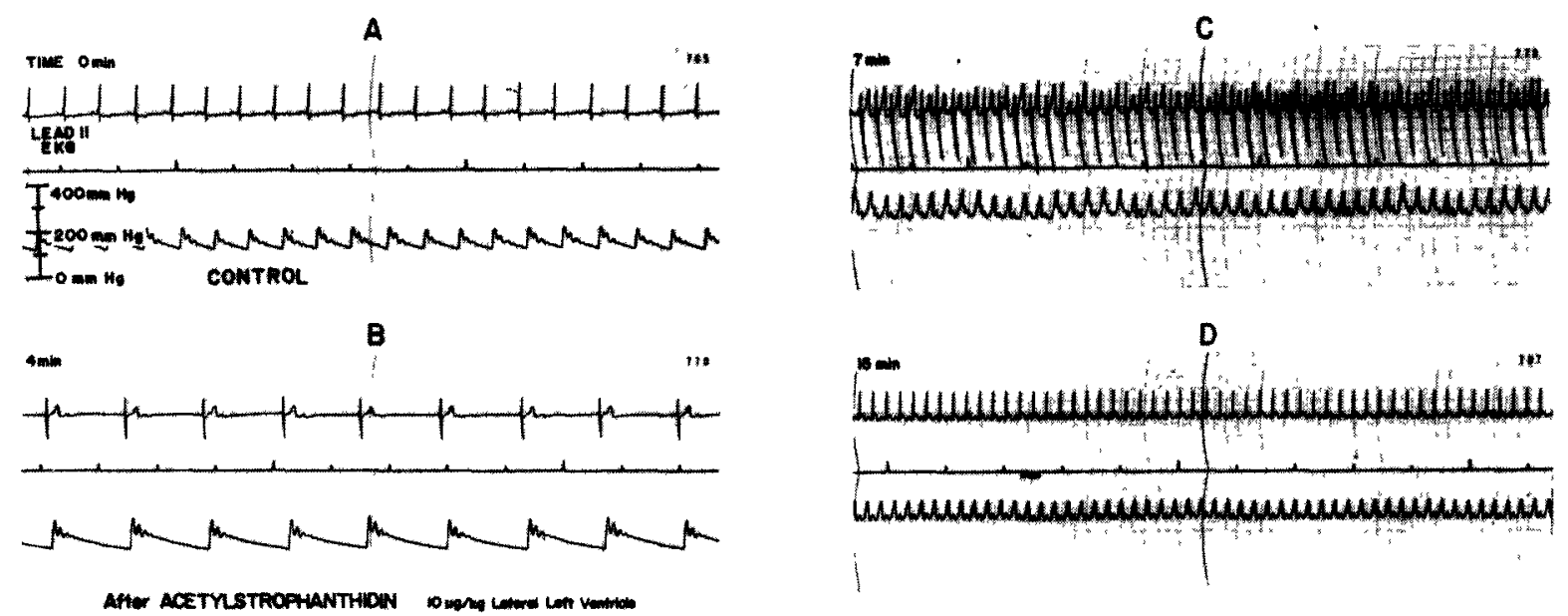

Fig. 1. The Lead II electrocardiogram is illustrated in the upper part of each Panel; arterial blood pressure is shown in the lower part. Panel A represents the control record. Nodal bradycardia is shown in Panel $\mathrm{B}$. Panel $\mathrm{C}$ llustrates the marked pressor response and the ventricular tachycardia. After $8 \mathrm{~min}$, Panel $\mathrm{D}$, the ventricular rhythm had reverted to a normal sinus rhy thm; systolic pressure was slightly decreased. 
lowed the injection of this dose of the drug into the left lateral ventricle of the brain. A typical response is represented in fig. 1 . The blood pressure sometimes showed a moderate decrease within the first ten minutes after the intraventricular injection of acetylstrophanthidin; this response was not consistent. A marked pressor response, $90-200 \mathrm{~mm} \mathrm{Hg}$, was always elicited by the central injection of acetylstrophanthidin, it followed the depressor response when the latter occurred. After $45-60 \mathrm{~min}$ at its maximum level, the blood pressure would begin to decrease spontaneously, but never decreased to control levels even after 4 hours had elapsed.

The early electrocardiographic changes that occurred within the first $10-20 \mathrm{~min}$ following the intraventricular injection of acetylstrophanthidin were not uniform from one experiment to another; sinus bradycardia, sinus tachycardia, nodal bradycardia, and ventricular rhythms were all observed durng this period in different animals. The latter changes were consistent and usually began as the blood pressure began to rise. There was a marked sinus tachycardia that progressed to a bigeminal rhythm; the sequence of events culminated in ventricular tachycardia or a multifocal ventricular rhythm. Neither ventricular fibrillation nor cardiac arrest ever resulted from the intraventricular injection of acetylstrophanthidin. The intraventricular injection of an equal volume of physiological saline did not produce these cardiovascular changes. The centrally-induced arrhythmias reversed spontaneously after $10-30 \mathrm{~min}$. Once reversed, the arrhythmias could not be elicited again with subsequent injections of acetylstrophanthidin, even when larger doses were used.

\subsection{Bilateral vagotomy}

Bilateral cervical vagotomy was performed in two animals. This procedure abolished the excessive bradycardia and atrioventricular nodal block induced by the central administration of acetylstrophanthidin, but it prevented neither the pressor response nor the occurrence of centrally-induced ventricular arrhythmias.

\subsection{Systemic administration of sympatholytic drugs}

Reserpine, $0.1 \mathrm{mg} / \mathrm{kg}$, was administered intramuscularly to five dogs on two consecutive days, experiments were performed on the fourth day. Cen-

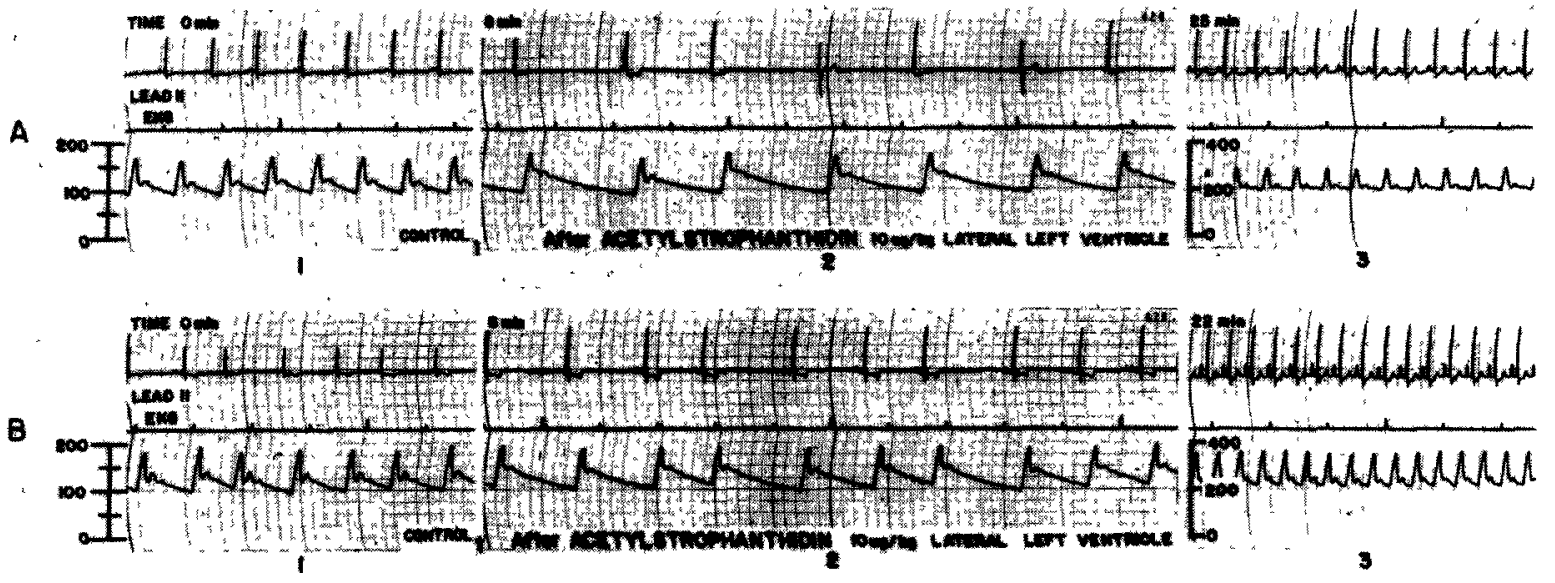

Fig. 2 Panels $A$ and B are records from two different dogs that had been pretreated with reserpine. In both Panels the blood pressure scale in Part 3 is twice that in Parts 1 and 2. Panel A: Part 1 was taken from the control record; heart rate, 70 beats/min. Acetylstrophanthidin was injected into the left lateral ventricle at the arrow between Parts 1 and 2 . Panel 2 shows the slow bigeminal rhy thm that developed; the blood pressure was unchanged. Part 3 illustrates the marked pressor response; although no ventricular rhythm developed, the heart rate increased to 120 beats $/ \mathrm{min}$. Panel B: Part 1 represents the control record. Acetylstrophanthidin was injected into the left lateral ventricle at the arrow between Parts 1 and 2. Sinus bradycardia is shown in Part 2 . the blood pressure was unchanged. Part 3 shows the sinus tachycardia and the marked pressor response. 
trally injected acetylstrophanthidin did not produce arrhythmias following reserpine pretreatment, however, a sinus tachycardia and a pressor response were elicited. Fig. 2 shows segments of records taken during two separate experiments

Systemic pretreatment of five different anımals with $d, l$-propranolol $(1.0 \mathrm{mg} / \mathrm{kg}$ intravenously $20 \mathrm{~min}$ before the central injection of acetylstrophanthidin) did not give consistent results. Neither ventricular arrhythmias nor pressor responses were elicited by the intraventricular injection of acetylstrophanthidin following $d, l$-propranolol pretreatment in two experiments, in both experiments a marked sinus bradycardia developed. However, the pressor responses and ventricular arrhythmias did develop after the central administration of acetylstrophanthidin in two additional animals that had been pretreated with $d, l$-propranolol. A fifth animal was pretreated with a larger dose of $d, l$-propranolol, $2.5 \mathrm{mg} / \mathrm{kg}$, all centrally induced responses occurred as in control anımals.

\subsection{Intraventricular administration of sympatholytic drugs}

The effects of the intraventricular injection of both $d$ - and $d, l$-propranolol on cardiovascular responses produced by centrally administered acetyl- strophanthidin were studied. The total dose of $d, l$ propranolol injected into the left lateral ventricle was $1.0 \mathrm{mg}$; if all of this dose were to gain access to the systemic circulation, the maximum dose attaned would be $0.11 \mathrm{mg} / \mathrm{kg}$. This dose is not sufficient to produce a significant blockade of beta-adrenergic receptors (Whitsitt and Lucchesi, 1967). Isoproterenol, $0.25 \mu \mathrm{g} / \mathrm{kg}$, was injected intravenously into each animal before and after the central administration of $d, l$-propranolol; there was no significant difference between the two chronotropic responses to isoproterenol. In four different dogs, the central injection of $d, l$-propranolol appeared to attenuate, in varying degrees, the cardiovascular changes produced by the central administration of acetylstrophanthidin. In one experiment, the development of ventricular arrhythmias and pressor response was prevented; in two others, the pressor response developed but the ventricular arrhythmias did not; in the fourth, the pressor response as well as some isolated ventricular beats occurred and these beats developed into a short run of ventricular tachycardia Although the ventricular arrhythmias appeared to be modified by the intraventricular injection of $d, l$-propranolol, the centrally-induced bradycardia was not. The results are similar to those obtained after reserpine-pretreatment. The $d$ -
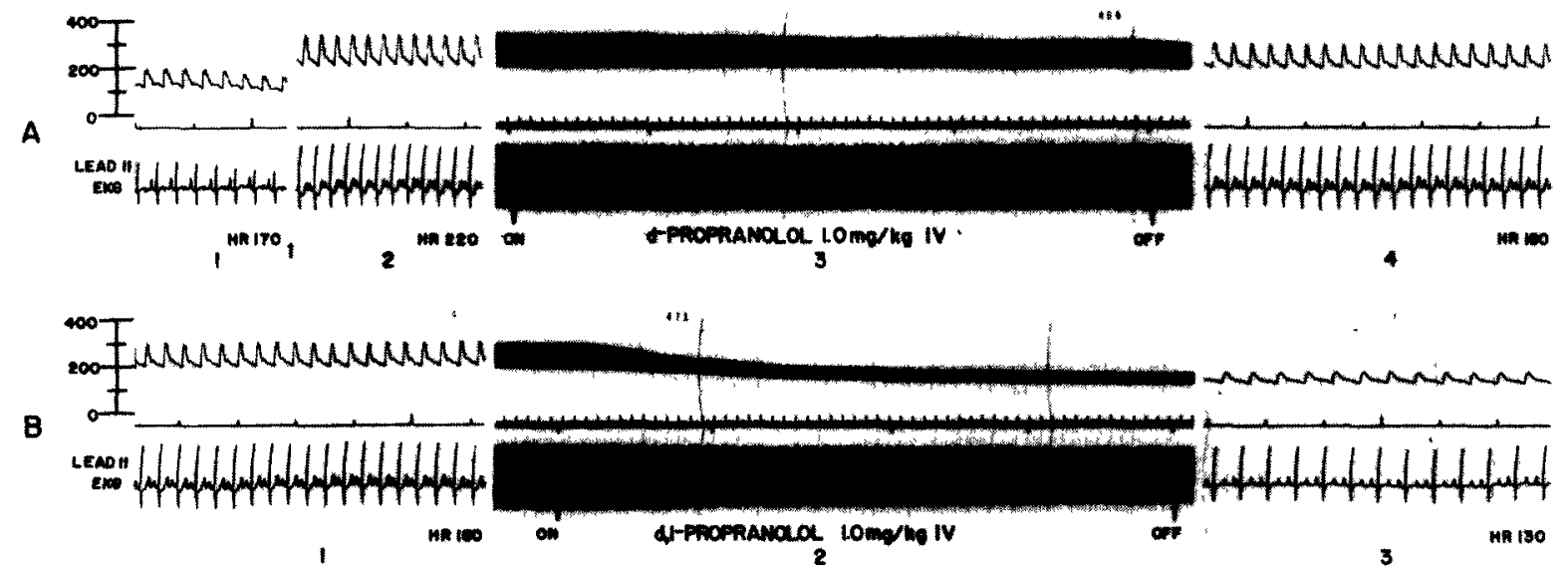

Fig. 3. Panels A and B show records taken from the same anımal. The upper part of each record shows the arterial blood pressure in $\mathrm{mm} \mathrm{Hg}$; the Lead II electrocardiogram ss shown in the lower part. Panel A Part 1 represents the control record. At arrow between Parts 1 and 2 acetylstrophanthidın was injected into the left lateral ventricle. Part 2 was recorded after the ventricular rhy thm had changed to a sinus tachycardia; blood pressure is still elevated. Part 3 shows the effect of a 5 min infusion of $d$-propranolol, $1.0 \mathrm{mg} / \mathrm{kg}$. Part 4 was taken $5 \mathrm{~min}$ after the $d$-propranolol infusion had been completed Panel $\mathrm{B}$. Part 1 is a contınuatıon of the record shown in A-4. Part 2 shows the marked decrease in blood pressure elicited by the 5 min infusion of $d, l$-propranolol, $1.0 \mathrm{mg} / \mathrm{kg}$. Part 3 was recorded $5 \mathrm{~min}$ after completion of $d, l$-propranolol administration. 
isomer of propranolol was administered centrally to five animals; it did not alter the cardiovascular responses to the intraventricular injection of acetylstrophanthidin.

\subsection{Modification of pressor response}

A marked pressor response was consistently produced by the intraventricular administration of acetylstrophanthidin. The response was not consistently modified by any of the procedures employed. Although no form of pretreatment prevented the pressor response from occurring, the response could be reversed once it had been produced by $d, l$ - but not $d$-propranolol. One and one-half min after the onset of centrally-induced ventricular arrhythmias, $1.0 \mathrm{mg} /$ $\mathrm{kg}$ of either $d$ - or $d, l$-propranolol was injected intravenously over a five-min period; five animals received the $d$-isomer and five additional animals received the racemic mixture. The $d$-isomer had very little effect on the pressor response $(p<0.1)$; however, $d, l$ propranolol significantly lowered the elevated blood pressure $(p<0.01)$. Fig. 3 llustrates the differential effect of $d$ - and $d, l$-propranolol in reversing the centrally-induced pressor response. The depressor effect appeared when a dose as small as $0.2 \mathrm{mg} / \mathrm{kg}$, of $d, l-$ propranolol was administered. The decrease in diastolic pressure was less than the decrease in systolic pressure; consequently, the pulse pressure was greatly reduced in all of the experiments. The blood pressure was never reduced below control values.

\section{DISCUSSION}

The cardiac arrhythmias and the pressor response elicited by the central injection of acetylstrophanthidin are similar to the changes evoked by the injection of other cardiac glycosides into the cerebral ventricles (Weinberg and Haley, 1955; Bircher et al., 1963). The drug-induced EKG changes closely resemble those that follow electrical stimulation of the lateral and posterior hypothalamus (Parker et al., 1962; Attar et al., 1963). Manning and Cotton (1962) and Bircher et al. (1965) have suggested that the ventricular arrhythmias induced by hypothalamic stimulation and those following the injection of cardiac glycosides into a cerebral ventricle are due to the activation of parasympathetic as well as sympathetic cardiac nerves. In the present investigation, only the excessive sinus bradycardia and atrioventricular nodal block induced by the central administration of acetylstrophanthidin were abolished when bilateral cervical vagotomy was performed before the intraventricular injection of acetylstrophanthidin. These results are in agreement with those of Hockman et al. (1966), but not those of Manning and Cotton (1962) or those of Parker et al. (1962).

Electrical stımulation of the hypothalamus as well as the intraventricular injection of cardiac glycosides produces a continuum of electrocardiographic changes that begins with sinus tachycardia and ends with a multifocal ventricular rhythm. Hockman et al. (1966) found that each arrhythmia could be elicited out of sequence by electrical stimulation with a specific stimulus intensity. The responses further along the continuum required greater stimulus intensities; thus, sinus tachycardia required the least and multifocal ventricular rhythm, the greatest stimulus intensity. Hockman et al. (1966) believe the dominant factor in the genesis of these centrally-induced arrhythmias to be the concentration of norepinephrine at the neuroeffector sites within the myocardium.

If the central administration of cardiac glycosides or electrical stimulation of the hypothalamus were causing the release of norepinephrine from adrenergic cardiac nerve endings, then the intravenous administration of $d, l$-propranolol or catecholamine-depletion by reserpine would be expected to prevent or modify the centrally induced arrhythmias. Indeed, Hockman et al. (1966) found that after $d, l$-propranolol (1.0 $\mathrm{mg} / \mathrm{kg}$ intravenously) electrical stimulation of loci in the diencephalon and mesencephalon had no observable effect on either heart rate or rhythm. However, in the present investigation $d, l$-propranolol $(1.0 \mathrm{mg} / \mathrm{kg}$ intravenously) prevented the occurrence of ventricular arrhythmias following the central administration of acetylstrophanthidin in two animals, but it was ineffective in blocking the arrhythmic response in three other animals. Different experimental methods might possibly explain the discrepancy between the results of the two different laboratories. However, if both stimuli produce arrhythmias by the same mechanism, i.e. norepinephrine which is released from cardiac sympathetic nerve endings, then response to either stimulus should be blocked by the intravenous administration of an adequate dose of $d, l$-propranolol. 
Reserpine-pretreatment prevented the development of ventricular arrhythmias following the central injection of acetylstrophanthidin to dogs with intact vagii; however, a sinus tachycardia developed and the pressor response was unchanged. Although the dose of reserpine used was sufficient to deplete myocardial and brain catecholamine stores, it is possible that the adrenal medulla was only partially depleted (Muscholl and Vogt, 1958). If this be the case, it is possible that the intraventricular injection of acetylstrophanthidin caused a release of adrenal medullary catecholamines. One must then postulate that the amount of amınes released was sufficient to produce a pressor response and a sinus tachycardia but not sufficient to produce ventricular arrhythmias.

Although the concentration of norepinephrine at the neuroeffector sites within the myocardium may play a role in centrally-induced arrhythmias, a central site of action for an adrenergic transmitter cannot be ruled out. Perhaps centrally-administered cardiac glycosides produce cardiac arrhythmias by effecting the central release of a substance, probably an adrenergic mediator, that is depleted by reserpine-pretreatment. Following reserpine-pretreatment, centrally administered acetylstrophanthidin did not produce ventricular arrhythmıs. Further evidence for this suggestion comes from experiments in which acetylstrophanthidin administered centrally following the intraventricular injection of $d, l$-propranolol falled to produce ventricular arrhythmias. Central administration of $d$-propranolol did not modify the ventricular arrhythmias produced by the intraventricular injection of acetylstrophanthidin. Although the racemic mixture of propranolol is found to be concentrated in brain tissue (Black et al., 1965), intravenously administered $d, l$-propranolol did not prevent the occurrence of cardiac arrhythmias following the central administration of acetylstrophanthidin. Cerebral distribution of drug following an intraventricular injection would not be expected to be the same as that following an intravenous injection, perhaps this difference contributes to the discrepancy in the results.

There is no doubt that cardiac glycosides injected into the cerebral ventricular system are capable of producing severe cardiac arrhythmias. The mechanism by which these arrhythmias is produced is not clearly understood, some of the evidence presented here suggests that an adrenergic transmitter may be involved. The fact that centrally-injected cardiac glycosıdes elicit cardiac arrhythmıs, in conjunction with results from experiments in which animals without a functioning sympathetic nervous system die in cardiac arrest suggest that lethal doses of cardiac glycosides may act, in part, on those areas of the central nervous system which regulate and modify peripheral sympathetic nervous system activity.

Although the cardiac arrhythmias produced by the intraventricular injection of acetylstrophanthidin were modified by reserpine-pretreatment and by intraventricular $d, l$-propranolol, the centrally-induced pressor response was not altered by any form of drug pretreatment used in the investigation. Sharpless and Rothballer (1961) have suggested that the pressor response is mediated by a non-catechol humoral substance. More recently Melville et al. (1963) have attributed the centrally-induced pressor response to increased sympathetic outflow. In the present investigation, reserpine-pretreatment had no effect on the pressor response. However, on the basis of these results alone, one cannot definitely rule out epinephrine or norepinephrine as the peripheral mediator of the pressor response because it is possible that the dose of reserpine used was not sufficient to thoroughly deplete the adrenal medulla. It is noteworthy that the racemic mixture, but not $d$-propranolol, was able to reverse the pressor response once it had occurred. The reversal by $d, l$-propranolol is interesting in that the blood pressure never fell below control values.

The mechanism by which $d, l$-propranolol reversed the pressor response is not clear. One possible explanation is that increased myocardial contractility and heart rate produce the pressor response. Therefore, $d, l$-propranolol reverses the pressor response by blocking myocardial beta-adrenergic receptors. However, if increased myocardial sympathetic activity alone were responsible for the centrally-induced pressor response, pretreatment with $d, l$-propranolol should prevent it.

In conclusion, the cardiac arrhythmias produced by the central administration of acetylstrophanthidin were prevented by reserpine-pretreatment and by the intraventricular injection of $d, l$-propranolol. No form of pretreatment prevented the centrally-induced pressor response; however, slow intravenous administration of $d, l$-propranolol reversed the pressor response once it occurred. It would appear that norepinephrine 
or epinephrine is involved in the cardiovascular changes produced by the injection of acetylstrophanthidin into the left lateral cerebral ventricle. One cannot assign a discrete locus of activity to the catecholamines; that is, they could be acting within the central nervous system as well as peripherally.

\section{REFERENCES}

Attar, H., M.Butierrez, S.Bellet and J.Ravens, 1963, Effect of stimulation of hypothalamus and reticular activating system on production of cardiac arrhythmia, Circulation Res. 12, 14.

Bircher, R., C.Chai and S.Wang, 1965, Effects of hexamethonium and tetraethylammonium on cardiac arrhythmias produced by pentylenetetrazol, picrotoxin and deslanos1de in dogs, J. Pharmacol. Exp. Ther. 149, 91.

Bircher, R., T.Kanai and S.Wang, 1963, Mechanısm of cardiac arrhythmias and blood pressure changes induced in dogs by pentylenetetrazol, picrotoxin, and deslanoside, J. Pharmacol. Exp. Ther. 141, 6.

Black, J., W.Duncan and R.Shanks, 1965, Comparison of some properties of pronethalol and propranolol, Brit. J. Pharmacol. 25, 577.

Boyajy, L. and C.Nash, 1966, Alteration of ouabain toxicity by cardiac denervation, Toxicol. Appl. Pharmacol. 6, 163.

Erlij, D. and R.Mendez, 1965, The modification of digitalis intoxication by excluding adrenergic influences on the heart, J. Pharmacol. Exp. Ther. 144, 97.
Hockman, C., H.Mauck and E.Hoff, 1966, ECG changes resulting from cerebral stimulation. II. A spectrum of ventricular arrhy thmias of sympathetic ongin, Amer. Heart J. 71,695 .

Lim, R., C.Liu and R.Moffitt, 1960, A stereotaxic atlas of the dog's brain (Charles C.Thomas, Springfield, Illinois)

Manning, J. and M.Cotton, 1962, Mechanism of cardiac arrhythmias induced by diencephalic stimulation, Amer. J. Phy siol. 203, 1120.

Melville, K., B.Blum, H.Shister and M.Silver, 1963, Cardiac ischemic changes and arrhy thmias induced by hypothalamic stımulation, Amer. J Cardiol. 12, 781.

Mendez, C., J.Aceves and R Mendez, 1961, The anti-adrenergic action of digitalis on the refractory period of the A-V transmission system, J. Pharmacol. Exp. Ther. 131, 199.

Muscholl, E. and M.Vogt, 1958, The action of reserpine on the peripheral sympathetic system, J Physiol. (London) $141,132$.

Nash, C., J.Alley and E.Manley, 1964, The suppression of ouabain toxicity by oxytocin and reserpine, Toxicol Appl. Pharmacol. 6, 163.

Parker, I., Jr., C Gunn and T.Lynn, 1962, Experimental centrogenic arrhy thmias, Clin. Res. 10, 179.

Sharpless, S. and A.Rothballer, 1961, Humoral factors released from intracranial sources during stimulation of retıcular formation, Amer. J. Physiol. 200, 909.

Stickney, J, B.Lucchesi and G.Abrams, 1966, Pharmacological alteration of the response of the mammalian heart to acetylstrophanthidin, Fed. Proc 25, 621 .

Weinberg, S. and T.Haley, 1955, Centrally mediated effects of cardiac drugs: strophanthin-K, quinidine, and procaine amide, Circulation Res. 3, 103. 